\title{
Reinventar el Mare Nostrum: el Mediterráneo como espacio de cooperación y seguridad
}

\section{Esther Barbé}

Catedrática de Relaciones Internacionales

Directora del Centre d'Estudis sobre ì Pau i el Desarmament

Universitat Autònoma de Barcelona. 98193 Bellaterra (Barcelona). Spain

\section{Resumen}

En noviembre de 1995 se va a celebrar una conferencia euromediterránea. El interés de los europeos por la estabilidad en el Mediterráneo ha dado lugar, en los últimos cinco años, a una multiplicación de foros políicos y de marcos de cooperación. La Unión Europea, junto a la UEO y la OTAN, están implicadas en este proceso.

Palabras clave: política mediterráneit, Unión Europea, diplomacia española, Mediterráneo occidental, OTAN, UEO.

Abstract. Rethinking the Mare Nostrum: the Mediterranean as an area for cooperatin and
security

A Eutomediterranean conference is going to take place in november 1995. European interest in Mediterranean stability has produced, during the last five years, a great number of political forums and frameworks for cooperation. The European Union, along with the WEU and NATO, are involved in this process.

Key words: Mediterranean politics, European Union, Spanish diplomacy, Western Mediterranean, NATO, WEU.

\section{Sumario}

Introducción

Dos orillas, un destino

Imaginación diplomática: el uso de la geometría variable

Un nuevo mundo: la rivalidad Este-Sur en la Unión Europea
Diálogo político: la mirada al sur de la UEO y la OTAN

A modo de conclusión: Barcelona 95

Bibliografía citada 
La región mediterránea se caracteriza por ese eterno dilema entre unidad de concepto y diversidad de hecho.

Francisco Fernández Ordóñez, 1990

\section{Introducción}

Durante el mes de noviembre de 1995 la presidencia española de la Unión Europea convertirá la ciudad de Barcelona en escenario de una conferencia euromediterránea. Acordada por el Consejo Europeo de Essen $(9$ y 10 de diciembre de 1994), esta "conferencia debería alcanzar un acuerdo sobre una serie de orientaciones económicas y políticas para la cooperación euromediterránea de cara al siglo XXI e instaurar un diálogo permanente y regular sobre todos los temas de interés común». A lo que los (todavia) Doce suman lo siguiente: "el Consejo Europeo ha expresado su inquietud frente al progreso de las fuerzas extremistas e integristas en varios paises del norte de Âfrica». 1 .

La convocatoria de esta conferencia parte, pues, de una inquietud entre los países europeos. Una inquietud que tiene mucho que ver con lo que López Garcia y Núñez Villaverde (1994:140) han denominado el "mito que asocia el Islam con el fanatismo". Mito al que los autores citados suman otro más, el "mito de la invasión", derivado de la comparación entre las proyecciones demográficas en las dos orillas del Mediterráneo. Es decir, el vuelco demográfico en el Mediterráneo que recogen las cifras: si la relación en 1960 era de 1 habitante en el Sur por cada 4,7 en el Norte, en el período 1990-2000 esta relación se calcula en 1 a 2 y de cara al año 2025 se prevé una cifra similar en las dos orillas, de alrededor de 170 millones de personas (Safit, 1993: 81).

Los dos mitos apuntados por el «ojo europeo» que aborda el análisis de la región mediterránea no son sino manifestaciones de dos grandes fracturas del sistema internacional: En primer lugar, el Mediterráneo se ajusta, en términos económicos, a la fractura Norte-Sur. De ahí que sea calificado de "frontera entre el mundo industrializado y el Tercer Mundon (Tovias 1994: 7). Sin ir más lejos, en 1992 la renta per cápita de un español era trece veces superior a la de su vecino marroquí. La proximidad geográfica contrasta, pues, con la lejanía económica. En segundo lugar, siguiendo la fractura más destacada en la posguerra fría -el choque entre civilizaciones (Huntington 1993)-, el Mediterráneo constituye la frontera entre el mundo musulmán y el mundo cristiano.

Términos como "reinventar" - recogido en el título de este artículo- o "repensar" son habituales entre los analistas de las relaciones internacionales

1. "Conseil Européen. Réunion des 9 et 10 décembre 1994 à Essen. Conclusions de la présidence" en Europe, núm. 6376, 11, diciembre de 1994, p. 11. 
en los últimos años. La desaparición del muro de Berlín ha desencadenado un proceso de cambios a nivel insernacional que ha afectado de manera directa (negociaciones de paz árabe-israelíes, guerra del Golfo) o indirecta (programas de reconstrucción económica para el este de Europa) a la orilla sur del Mediterráneo. Tanto es así que el Mare Nostrum ha dado lugar a nuevos planteamientos teóricos, combinados con programas de actuación. Este artículo centra su interés, justamente, en los mencionados programas de actuación. Lo que nos obliga a revisar, sucesivamente, los presupuestos teóricos de partida, la voluntad política de las partes y los instrumentos de actuación. En otras palabras, Barcelona 95 como resultado de una visión global del Mediterráneo en la que las instituciones europeas hacen frente a riesgos sociales, económicos y políticos latentes en la orilla sur del Mare Nostrum.

\section{Dos orillas, un destino}

¿Existe una región mediterránea? ¿Se puede hablar de una zona de interés global?

Durante largos años la visión global del Mediterráneo estuvo ligada, más allá de la evidencia geográfica (el propio mar), a la geoestrategia mundial (Barbé, 1984). De tal manera que la existencia de una región mediterránea venía determinada por la estrategia de las dos superpotencias que en ella desplegaban, frente a frente, sus flotas navales y aéreas.

El reduccionismo gecestratégico ha dado paso a un enfoque más complejo del Mediterráneo, en el que el término de globalidad desempeña un papel central. Tanto es así que los analistas de la seguridad han tomado el caso mediterráneo como paradigmático para aplicar los nuevos enfoques de la seguridad global $^{2}$. Estos enfoques tratan, junto a los temas tradicionales de la seguridad como las materias estratégicas o los conflictos armados, los problemas medioambientales o las cuestiones socioculturales. El Mediterráneo, mar militarizado, polucionado y cuna de la civilización, goza de todos los atributos para atraer el interés del analista de la seguridad global.

La visión multidimensional de la seguridad global (defensa, ecología, economía, migraciones, derechos humanos, etc.) plantea de nuevo la pregunta de partida: ¿Mediterráneo o Mediterráneos? Es decir, la voluntad prescriptiva del analista de la seguridad global - conformar un espacio de cooperación en el Mediterráneo- se ha de preguntar si existen suficientes elementos en común para abordar la región en su conjunto.

Esta cuestión ha sido abordada por un gran número de obras en los últimos años. Paradójicamente, la noción de globalidad está vinculada a la idea del Mediterráneo como zona de frontera (fractura o división). Así lo recoge, por ejemplo, un informe de la Fundación Bertelsmann: «El Mediterráneo es más

2. Véase, en estas páginas, el artículo de Rafael Grasa sobre "El Mediterráneo desde una perspectiva globalizadora de la seguridadn. 
que un mar común a los países que lo rodean. De hecho es una red densa, formada por una diversidad de líneas divisorias. Esto es, líneas divisorias entre sistemas económicos y de seguridad diferentes, entre sistemas políticos y culturas políticas diferentes, y entre diferentes lenguajes, formas de expresión y denominaciones religiosas" (Weidenfeld, 1991:7).

Esta red - productora, en principio, de conflictos y de tensión- puede jugar las veces de "unificadora" del espacio mediterráneo. Esta es la conclusión que se puede extraer de la guerra del Golfo, en la que las sociedades de la ribera sur del Mediterráneo desempeñaron la función de "correa de transmisión" entre la zona de conflicto y la seguridad europea. En efecto, el usentimiento en dichas sociedades de pertenencia a una comunidad árabe-musulmana (persas, beréberes o cristianos no tienen por qué excluirse, dado que pueden identificarse con uno u otro de los caracteres comunitarios) convierte el espacio geográfico que se extiende entre Irán (algunos apuntan hasta Pakistán) y Mauritania en un espacio permeable» (Barbé, 1991: 57). Sami Nä̈ (1991) ha hablado de "unidad y profunda imbricación del conjunto de los problemas que se plantean en la vertiente sur del Mediterráneo". De ahí que Barry Buzan (1991: 190) haya definido el mundo árabe-musulmán como un complejo de seguridad, entendiendo por tal «un grupo de estados cuyas preocupaciones básicas en materia de seguridad los vinculan entre sí, a tal extremo que es imposible considerar sus seguridades nacionales las unas al margen de las otras" ${ }^{3}$. Este complejo de seguridad ha sido verificado durante los largos años del conflicto árabe-israelf.

La existencia del complejo de seguridad árabe-musulmán, por una parte, y la adopción por parte de las diplomacias europeas de una concepción multidimensional de la seguridad ${ }^{4}$, por otra, han favorecido los planteamientos globalizadores del Mediterráneo, en términos temáricos y geográficos. Lo que no comporta, a priori, ni conflicto ni cooperación. Basándose en Fernand Braudel, Roberto Aliboni (1991:2) nos recuerda que uel Mediterráneo es una encrucijada, abierta a las influencias y a los intercambios, y por tanto a la cooperación y a la seguridad tanto como al conflicto y a las tensiones; una encrucijada, sin embargo, que aún divide diferentes partes del Mediterráneo. Ello significa que la cooperación y la seguridad son posibles, pero no se pueden dar por asumidas. Requieren un esfuerzo de voluntad y comportamientos adecuados".

3. Las otras zonas del mundo que constituyen complejos de seguridad son: América Latina, África Austral, sur de Asta y Sudeste asiático.

4. La concepción multidimensional de la seguridad es adoptada, de manera tardía, incluso por la OTAN: whora es posible sacar todas las consecuencias de los elementos políticos, de seguridad y estabilidad y de sus dimensiones económicas, sociales y medioambientales, además đe la indispensable dimensión defensiva. Ante los distintos retos con que se enfrenta la Alianza se impone una concepción amplia de la seguridad", en Nuevo concepto estratégico de la Alianza (aprobado por los jefes de estado y de gobierno en la reunión del Consejo del Atlántico Norte, celebrada en Roma del 7 al 8 de noviembre de 1991). 
Eso es lo que lleva a preguntarnos por la voluntad política mostrada y por los comportamientos adoptados en los últimos años en lo que se refiere a la creación de un espacio de cooperación y de seguridad para el Mediterráneo. Preguntémonos, pues, por la imaginación diplomática.

\section{Imaginación diplomática: el uso de la geometría variable}

La idea de crear un espacio de cooperación y seguridad en el Meditertáneo no es nueva. Antes de la caída del muro de Berlín el tema había generado dos tipos de propuestas. En primer lugar, las propuestas de carácter global y multilateral —capírulo en el Acta Final de Helsinki (1975), propuestas de la Unión Soviética (1986) y de los no alineados (1987), resolución de la Asamblea General de Naciones Unidas (1982) - que tuvieron un efecro muy limitado, dados los constreñimientos de la bipolaridad. En segundo lugar, hay que hacer mención de otro tipo de propuestas, más vinculadas a Europa Occidental y con objetivos temáticos o geográficos limitados. En esa política de petits pas destaca el papel desempeñado por Francia.

En la polírica de petits pas se suman proyectos que no ven la luz - la propuesta del presidente Mitterrand ante el parlamento marroquí, en enero de 1983, de convocar una conferencia del Mediterráneo occidental- por su carácter prematuro, con iniciativas puntuales, entre otras: los encuentros culturales de Hydra, organizados por Jack Lang en 1982; el seminario económico de Gredos, de 1986; la iniciativa Bersani del Intergrupo Mediterráneo del Parlamento Europeo, de 1987, y el lanzamiento del Foro Mediterráneo, organizado por primera vez en Marsella en 1988. Jacques Huntzinger (1989: 5), responsable del proyecto del Foro Mediterráneo impulsado por el Quai d'Orsay, abordaba el tema de la cooperación en la región en los siguientes términos: «el establecimiento de una cooperación mediterránea no debe dar lugar, a medio plazo, ni a una construcción política grandiosa y ambiciosa, ni a un pacto estratégico, ni a una organización internacional más. La perspectiva debe ser concreta, pragmática, flexible y operativa».

Las transformaciones del sistema internacional, a partir de la caída del muro de Berlín y la descomposición del bloque del Este, van a resituar el tema de la cooperación y la seguridad en el Mediterráneo. En efecto, las primeras apreciaciones sobre el tema están directamente vinculadas a los cambios en Europa del Este. A finales de 1989, el presidente González, en una visita a Marruecos, advertía del peligro de los "nuevos vecinos". Es decir, que los vecinos del Este ocuparan en la agenda comunitaria un espacio antes reservado a los países de la ribera sur del Mediterráneo, desplazándolos así en el terreno financiero. En otras palabras, el Este se convierte en una rival para el Sur, lo que genera reacciones entre los países árabes afectados, como es lógico, pero también entre los miembros mediterráneos de la Comunidad. El activismo tradicional de Francia en materia mediterránea va a solaparse, en este caso, con la diplomacia española. El motor hispano-francés parte, sin embargo, con una disfuncionalidad que los años van a corregir. En efecto, las estrategias propuestas por 
Francia y por España son, en un primer momento, diferentes. Así, Francia mantiene la concepción desarrollada en los últimos años de la guerra fría, centrada en el Mediterráneo Occidental y altamente pragmática. España, por su parte, se lanza a un proyecto de ingeniería diplomática mucho más complejo, para el que va a contar con el apoyo italiano.

En el primer semestre de 1990, Fernández Ordóñez hacía mención a las propuestas españolas para el Mediterráneo, basadas en la experiencia de la $\mathrm{CSCE}^{5}$. El ministro español se preguntaba: "¿Por qué no aplicar a la región mediterránea el mismo modelo que ha dado tan buenos resultados en Europa? ¿Por qué no desarrollar un sistema giobal para promover la estabilidad, garantizar la seguridad y prevenir las crisis? Un sistema que tenga en cuenta, con una visión global y equilibrada, todos los aspectos de la seguridad, que favorezca el desarrollo económico y estimule el diálogo intercultural. En suma, ¿por qué no convocar una Conferencia sobre la Seguridad y la Cooperación en el Mediterráneo" (Fernández Ordóñez, 1990: 9-10).

El proyecto de la CSCM ve la luz pública bajo la forma de proyecto hispano-italiano, presentado en la reunión de la CSCE sobre problemas ecológicos en el Mediterráneo, celebrada en Palma de Mallorca (setiembre de 1990). Este proyecto tuvo que convivir con un background muy especial - la crisis y, finalmente, la guerra del Golfo- que, sin duda, incidió en su destino. Para empezar, la CSCM, recogida en 1991 en un documento conjunto de España, Italia, Francia y Portugal, pasa a definirse como "paraguas" o "estructura de acompañamiento a los arreglos poscrisis del Golfo y a la resolución de la cuestión palestina" ${ }^{6}$, lo que nos permite pensar en términos de complementariedad y no de alternativas excluyentes. Aspecto importante, como veremos más adelante. A la idea de complementariedad se suman otras dos, que inciden plenamente en temas y problemas ya planteados aquí. Nos referimos a los dos grandes criterios que deberían articular la CSCM: globalidad y progresividad.

El criterio de globalidad se refiere al ámbito (la región mediterránea en sentido amplio, incluyendo Oriente Medio y el Golfo), a la participación (países de la región o con intereses en la región) y al contenido (todos los temas que afecten a la cooperación y a la seguridad, siguiendo la lógica de una agenda globalista). El criterio de progresividad comporta el carácter selectivo y la naturaleza expansiva del proceso. Lo que permite, de entrada, dejar fuera de la agenda los temas "disruptivos" por definición.

La metodología CSCM muestra, en un principio, una opción divergente respecto de la política francesa, ya mencionada. Se puede decir que la metodología francesa (ámbito limitado a la zona del Mediterráneo occidental y agenda de trabajo técnico-funcional) subyace en el proceso Cuatro (España, Francia,

5. Véase, en este mismo número, el artículo de Nora Sainz titulado "La dimensión medirerránea de la Conferencia sobre la Segutidad y la Cooperación en Europa: de región limítrofe a campo de aplicación.

6. "Conferencia para la Seguridad y la Cooperación en el Mediterráneo" (documento conjunto de España, Francia, Italia y Portugal). Madrid; Oficina de Información Diplomácica, 1991, p. 2. 
Portugal e Italia) más Cinco (miembros de la UMA), Ianzado en 1990 por la diplomacia italiana, al que se suma Malta en 1991. ¿Cómo articula España su política, a priori contradictoria, en ambos proyectos?

Miguel Angel Moratinos (1991: 18-19), diplomático español especializado en temas mediterráneos, respondia asi: "Junto a Italia, Francia y Portugal, mi país comenzó a reflexionar coordinadamente sobre el futuro del Mediterráneo occidental. Se privilegió esa parte de nuestro mar común por su homogeneidad, la ausencia de conflictos abiertos y los lazos históricos, culturales y de toda indole existentes entre sus dos riberas [...] No obstante, la percepción espanola sigue convencida de que los problemas, retos y desafios existentes en la cuenca mediterránea necesitan un marco más global [...] La seguridad en el Mediterráneo no es algo que se pueda compartimentar o dividirn.

La evolución de los acontecimientos (aislamiento de Libia, guerra civil en Argelia, lentitud del proceso de paz en Oriente Medio) ha dejado el proyecto de la CSCM en el terreno de las referencias simbólicas, como la de la Asamblea del Atlántico Norte (febrero de 1993), o ha "revivido", simbólicamente, en el diálogo mediterráneo impulsado por Egipto, cuya primera reunión a nivel ministerial tuvo lugar el 4 de julio de 1994 en Alejandría. El diálogo, limitado por el número de participantes (los Cuatro más Egipto, Marruecos, Argelia, Túnez, Grecia y Turquía), ha mostrado rápidamente la división entre el enfoque francés más orientado a problemas concretos y el ambiente general, deseoso ante todo de mantener un canal de comunicación política abierto. El marco Cinco más Cinco se ha visto igulalmente afectado por los problemas antes mencionados (Libia, Argelia).

Ello nos lleva, en nuestra opirión, a la situación de hecho existente en materia de cooperación en el Mediterráneo, definida en un término muy propio de la construcción europea: geometría variable. En efecto, a diferencia del proyecto arquitectónico de la CSCM, los acontecimientos se han encargado de tejer a lo largo de los ańos noventa una red compleja y multiforme entre las orillas norte y sur del Mediterráneo, en la que predominan los núcleos duros (como los Cuatro), las iniciativas particulares (papel de Egipto) y las relaciones bilaterales entre estados, y en la que, por encima de todo, cobran protagonismo las organizaciones europeas, destacando el papel de la Unión Europea. De ahí que nos interesemos por la política mediterránea de los Quince.

\section{Un nuevo mundo: la rivalidad Este-Sur en la Unión Europea}

«El primer círculo de la CEE es la propia CEE. El segundo círculo son los páses del Sur: los países ACP y los países árabes, y entre estos últimos, los países árabes del Mediterráneo Surn (Khader, 1992: 177). Esta afirmación, válida durante muchos años, entra en crisis a finales de los años ochenta. La puesta en marcha del Plan Phare, en julio de 1989, o del BERD, en enero de 1990, son evidencias de una opción política: la voluntad y los recursos de Europa Occidental en la posguerra fría se centran en la recuperación económica de los pafses de Europa Central y Oriental (Pecos). Lo que, en términos de coope- 
ración, comporta que en el período 1992-1996 la Comunidad haya dedicado cinco veces más recursos al Este que al Mediterráneo.

La voluntad de corregir dicha política ha partido, como no podía ser menos, del lobby mediterráneo en el marco de la Unión Europea. La idea de una política mediterránea de la Comunidad tomó cuerpo, por primera vez, en la cumbre de jefes de estado y de gobierno de los entonces Seis, celebrada en París en 1972. A iniciativa del presidente Pompidou, la Comunidad unió a la mecánica bilateral seguida hasta ese momento una lógica global, que pretendía aplicar un mismo esquema (acuerdos de cooperación) a todos los países del Magreb y del Machrek. Esquema que reflejaba «el sentido de misión y de intereses propios de la Comunidad en el mundo mediterráneos (Ginsberg, 1989: 117). Dichos acuerdos preveían esencialmente preferencias comerciales, cooperación financiero-técnica y contactos institucionales. Esta política, tildada de grandilocuente (Dinan, 1994: 459), obtuvo escasos resultados. Al resultado negativo per se se sumó el ingreso, en los años ochenta, de España, Grecia y Portugal a la Comunidad, con la consiguiente merma para las ventajas de los países terceros del Mediterráneo en el terreno comercial (Tovias, 1990; Khader, 1992).

En lo que respecta al diálogo político -comprendido en la lógica de una política global-, los Nueve pusieron en marcha a través de la Cooperación Política Europea, y como resultado de la guerra del 73, el Diálogo Euro-Árabe, teniendo como interlocutor a la Liga Árabe (lo que ampliaba geográficamente la lógica mediterránea). En este caso, nos hallamos ante un nuevo fracaso (Aliboni, 1990: 156), ya que en ningún momento se llegó a establecer, con todas sus consecuencias, el trade-off deseado por el mundo árabe como base para el éxito del diálogo; es decir, la garantía del petróleo árabe a cambio de apoyo europeo pleno en el conflicto árabe-israelí.

A finales de 1980, momento en el que se transformaron las condiciones globales del sistema internacional, las relaciones entre la Comunidad y sus socios mediterráneos están claramente desequilibradas a favor de la primera (Khader, 1992: 206). Se ha creado una situación de dependencia o de asimetría (López García y Núñez Villaverde, 1994: 129) reflejada en los déficit comerciales de los países mediterráneos respecto de la CE.

Los países árabes del Mediterráneo, en general, y el Magreb, de manera particular, van a atraer nuevamente la atención de la Comunidad, una vez superado el "espejismo" de la Europa del Este. Las migraciones hacia la Comunidad, desde el Magreb y Turquía, sumadas a la tensión creada por la guerra del Golfo, explican el "redescubrimiento" del Mediterráneo por parte de los Doce. Remy Leveau (1992: 204) elabora un diagnóstico de la situación social que nos puede ayudar a "situar» la política mediterránea de los Doce en los años noventa: «El Estado providencia y las imágenes de las televisiones europeas proyectadas hoy directamente a millones de telespectadores del Magreb o de Turquía crean, a la vez, una fascinación y una frustración que se traducen en un deseo de otros lugzares, en una voluntad de partida que afecta sobre todo a los jóvenes. Pero las imágenes transportan también la percepción de una sociedad inaccesible que los rechaza y justifica un repliegue de identidad 
que favorece los movimientos islamistas. A corto plazo, esta evolución se traduce también por un nuevo éxodo de clases medias de formación moderna que no encuentran hoy su puesto en las sociedades magrebies".

Todo ello lleva a caracterizar, como indican algunos analistas con preocupación (Lorca, 1992: 9), a los vecinos del Sur como «zona de fricción», frente a un Este considerado "zona de cooperación». En cualquier caso, lo cierto es que las presiones del lobby mediterráneo en la Comunidad (España, Francia e Italia) van a impulsar un nuevo enfoque de las relaciones con los países del Mare Nostrum. La Política Mediterránea Renovada (PMR), adoptada en diciembre de 1990, se caracteriza por dos cosas: 1) un aumento de los montantes financieros para el período 1992-1996, y 2) el Consejo avanza por la vía del diálogo político, al hacer referencia, por primera vez, al respeto de los derechos humanos y a la promoción de los valores democráticos.

El aumento de la contribución financiera para el período 1992-1996, que prácticamente se triplicó respecto del período anterior (1987-1991), merece, sin embargo, algunas críticas dada su composición: «un mayor peso de los préstamos del BEI, en detrimento de la parte correspondiente a los donativos y a las subvenciones" (Khader, 1992: 221).

En lo que respecta a los derechos humanos, el tema planteó muy pronto diferencias de interpretación entre las instituciones comunitarias. Destaca la actitud del Parlamento Europeo, que en febrero de 1992 no aprobó la aplicación de los cuartos protocolos financieros, previstos en la PMR, para Marnecos, a causa del estado de los derechos humanos en dicho país ${ }^{7}$. Esta actitud del Parlamento dio lugar a una contraofensiva diplomática del comisario encargado del Mediterráneo, el español Abel Matutes, y del mismo gobierno español.

El "mar de fondon - La presión marroquí en torno a los acuerdos de pescase convierte en un acicate para "teinventar" una salida dentro de la PMR. Vistas las dificultades en 1992 de seguir adelante con el proceso Cinco más Cinco (a causa de Argelia y de Libia), la vía comunitaria per se sigue siendo la más interesante para todas las partes (legitimidad, marco institucional, recursos). No olvidemos que Marruecos había presentado, en 1987, su solicitud de ingreso a la Comunidad, rechazada por el carácter no europeo del país ${ }^{8}$. De ahí que la propuesta surgida del Consejo, en marzo de 1992, de explorar la posibilidad de una zona de libre cambio para Marruecos (e incluso para Argelia y Túnez), sea capaz de desactivar la "bomba de relojería» puesta en marcha por el Parlamento Eutopeo.

El realismo de la diplomacia española, cuyos intereses son los más directamente afecctados en el tema pesquero, conduce al Consejo hacia una nueva etapa en las relaciones de la Comunidad con el Magreb. Una etapa que ahon-

7. Véase el tema en detalle, en estt: número, en el artículo de Águeda Urruela sobre "El Parlamento Europeo frente al conflicto del Sáhara Occidental".

8. En el misno 1987, Turquia presentó su solicitud de ingreso, rechazada en 1989. En 1990, Malta y Chipre presencaron sus peticiones de ingreso. 
da en las diferenciaciones dentro del marco global mediterráneo y que será ratificada por el Consejo Europeo de Lisboa (junio de 1992), en el que se recoge la idea de una asociación euro-magrebí que debería incorporar una zona de libre cambio; diálogo político, y cooperación económica, técnica, financiera y cultural. Este paso adelante de los Doce muestra que el área del Magreb está ganando carácter propio, en la línea del proyecto francés de Mediterráneo occidental, si bien los cambios políticos en Argelia van a impedir toda aproximación subregional. La región mediterránea, y el Magreb en concreto, se resisten a favorecer la filosofia de la Comunidad a nivel mundial, centrada en las relaciones "grupo a grupo".

Los grandes proyectos del 92 en materia mediterránea se ven diluidos por las circunstancias. Así, en 1994, los Doce estaban desempeñando un papel más que discreto en la Conferencia de Paz de Oriente Medio - destaca su ayuda financiera a los territorios ocupados - a la vez que los procesos negociadores abiertos con paises de la región (Túnez, Martuecos, Israel y Turquía) se hallaban estancados. Todo ello sitúa la política mediterránea en un lugar desfavorecido frente al avance de los Pecos - puestos en el camino de la adhesióny a la ampliación hacia el Norte, al pasar de Doce a Quince.

Esta situación activa, nuevamente, al lobby mediterráneo, cuya inquietud es recogida por el Consejo Europeo de Corfú (junio de 1994) y convertida unos meses después en una iniciativa de la Comisión, tendente a reformular la polftica mediterránea. El motor franco-español impulsa, unza vez más, el "paso adelante» en materia mediterránea.

En esta ocasión, el "paso adelante» suma a los métodos ya conocidos -acuerdos de asociación, conferencia mediterránea - una idea fija: el carácter especular del Sur con respecto al Este. De ahí la voluntad de dotar al marco mediterráneo de los instrumentos probados en Europa (Espacio Económico Europeo, BERD, Plan Phare). Desde el segundo semestre de 1994, esa idea filtra las informaciones que proceden desde Bruselas. Así, «Francia y España están de acuerdo sobre la necesidad de que la Unión Europea mantenga ta proporción en su apoyo a los países de Europa Central y Oriental, por un lado, y a los países mediterráneos (magrebíes, en particular), por otro. Según fuentes diplomáticas, España sería favorable a una fórmula de programa Phare mediterráneo" ${ }^{10}$.

El Consejo Europeo de Essen (diciembre de 1994), celebrado a 21 (los Quince recibían como invitados a los seis Pecos), es, de momento, la última etapa en la política de la Unión hacia el Mediterráneo. En su discurso frente a los jefes de estado y de gobierno, Jacques Delors hablaba de «la imagen de los países del Norte, en especial de la presidencia alemana, que han comprendi-

9. La Unión Europea es el primer donante de ayuda para los palestinos. A pesar de ello, sólo se han recibido 60 de los 700 millones de dólares prometidos para un período de cinco años. Véase el tratamiento del tema durante el encuentro de la Troika con Arafat y Peres en Europe, núm. 6376, 30 de noviembre de 1994.

10. Cirado pot el bolecin Europe, núm. 6326, 30 de setiembre de 1994, p. 10. 
do que es necesario un message fort para el Sur; a partir de ahí, las presidencias francesa y española van a poder elaborar una política "ambiciosa" para una región en la que ya estamos muy presentes " ${ }^{11}$. El motor franco-español, encargado sucesivamente de la presidencia de la Unión en los dos semestres de 1995, ha de recoger un testigo "envenenadon. En efecto, a pesar de las palabras de Delors, la fractura Norte-Sur en el marco de los Quince es una evidencia a la hora de asignar recursos. De ahí, por tanto, que se deba distinguir entre las grandes concepciones, los proyectos de orden político y las decisiones que comportan asignación de recursos concretos.

En el primer caso - grandes concepciones-, el Consejo de Essen se reafirma en una idea asumida a lo largo de los años: «el Mediterráneo constituye para la Unión Europea una zona prioritaria de importancia estratégica” ${ }^{12}$. En lo que respecta a los proyectos políticos, el "Consejo Europeo se felicita de la intención manifestada por la futura presidencia española de organizar, en el segundo semestre de 1995, una conferencia ministerial euromediterráneas y, más allá de ese proyecto, la Unión Europea kaprueba la idea general y los objetivos de una asociación euromeditertánean.

La asignación concreta de recursos constituye el tercer aspecto apuntado. Es ahí, justamente, donde el valor de la región mediterránea como zona prioritaria despierta aproximaciones diferentes. En efecto, la voluntad franco-española de reasignar recursos entre el Este y el Sur —debidamente recogida por la iniciativa de la Comisión y traducida en una propuesta de ayudas, para el período 1995-1999, de 5.500 millones de ecus para el Mediterráneo frente a 7.000 para los Pecos- choca frontalmente con la opción del norte (Gran Bretaña, Dinamarca y Holanda). En efecto, estos países son contrarios a esa nueva distribución de recursos y se muestran partidarios de respetar la lógica del período 1992-1996, de cinco a uno en favor de los Pecos.

La prioridad del Mediterráneo, justificada con la frialdad de las cifras económicas (dependencia energética e intercambios comerciales), va más allá. No en vano el Consejo Europeo de: Essen expresaba — recogido en nuestra introducción-inquietud frente a la evolución política del norte de África. Tema que, más allá de las cuestiones económicas, incide en los temas políticos y en la defensa. De ahí nuestro interés por el diálogo político entre las dos orillas, que comporta la mirada hacia el sur de la UEO y de la OTAN.

\section{Diálogo político: la mirada al sur de la UEO y la OTAN}

En materia de diálogo político, la iniciativa ha partido, una vez más, del seno de los Cuatro (destacando el papel del gobierno español). Así, en el marco de la PESC (Grupo de Trabajo sobre la Seguridad), de la UEO o de la OTAN,

11. Citado por el boletín Europe, núm. 6376, 11 de diciembre de 1994, p. 1.

12. Ésca y las siguientes referencias al Consejo Europeo de Essen proceden de "Conseil Europeen. Réunion des 9 et 10 décembre 1994 à Essen. Conclusions de la présidence». Europe, núm. 6376, 11, diciembre de 1994. 
España ha defendido en todos los foros la vinculación entre estabilidad europea y estabilidad mediterránea ${ }^{13}$. Esa idea ha quedado sucesivamente recogida en los textos programáticos de la Unión Europea (como muestra la declatación del Consejo de Essen o los textos de la PESC), de la UEO (Declaración de Petersberg, 1992, y posteriores) y de la OTAN (Declaración del Consejo Atlántico de Bruselas, 1994). La conferencia euromediterránea de Barcelona supone, en términos simbólicos, la culminación de la política de vinculación entre las organizaciones europeas y el mundo mediterráneo.

Igual que en el caso de la Unión Europea, se puede hablar de la defensa por parte de España de una política especular, tendente a crear en el marco de la OTAN y de la UEO procesos paralelos a los seguidos por esas organizaciones en sus relaciones con los países del Este. Así, por ejemplo, el ministro García Vargas propuso en la reunión de ministros de defensa de la OTAN (Sevilla, setiembre de 1994) una asociación con los países del Mediterráneo equivalente a la Asociación para la Paz, firmada con el ex-bloque del Este.

Las circunstancias en el Magreb (aislamiento libio, proceso argelino) han obligado, con el paso del tiempo, a alterar uno de los supuestos fundamentales de la política española, y por extensión de los Cuatro: el establecimiento del diálogo grupo a grupo partiendo, en el caso del Magreb, de la existencia de la UMA. La política desarrollada por la UEO, iniciada con la creación de un Grupo de Trabajo sobre el Mediterráneo, en 1987, y desarrollada desde 1992 a través de encuentros semestrales, se ha centrado finalmente en una política de petits pas, así definida en noviembre de 1994 por el anterior secretario de la UEO, M. Van Eekelen, consistente en diálogos individuales con tres pafses del Magreb - Marruecos, Túnez y Mauritania-, a los que se ha sumado Egipto (decisión contenida en la Declaración de Kirchberg, mayo de 1994). El objetivo esencial de dichos diálogos ha sido el desarrollo de posibles medidas de confranza Norte-Sur, pero también Sur-Sur ${ }^{14}$. De ahí el interés, para que fuera efectivo, de contar con todos los países de la UMA.

A la hora de ilustrar el sentido dado a la noción de medidas de confianza en el marco aquí apuntado se puede señalar la invitación tealizada a observadores de Argelia, Túnez y Marruecos para asistir, en noviembre de 1994, a unas maniobras aeronavales de España, Francia e Italia en la zona del cabo de Gata. En efecto, la desconfianza en el caso del Mediterráneo occidental ha estado asociada al potencial militar de la OTAN y a los proyectos de creación de nuevas fuerzas, como el euroejército del Sur (con presencia de España, Francia e Italia) (Faria, 1994: 54). De ahí que en la mencionada reunión de Sevilla, el ministro español de defensa destacara ante sus colegas de la OTAN sus gestiones en los países del Magreb, tendentes a transmitir dos ideas: 1) que la

13. El ministro Solana ha atribuido a España la iniciaciva de los procesos de acercamiento al Medirerráneo, tanto en la UEO como en la OTAN, según declaraciones propias en conferencia sobre "La politica española mediterránea" (ICEM, 18, enero de 1994).

14. Informaciones sobre el contenido del diálogo entre la UEO y los países del Magreb, a través de la entrevista con Miguel A. Moratinos (ICMA, 13, mayo de 1993). 
Alianza no es ofensiva, sino defensiva, y 2) que la Alianza es tanto una organización política como militar.

Reforzar dichas ideas va a ser, de hecho, el primer paso del secretario general de la OTAN para implementar el diálogo entre la OTAN y algunos países mediterráneos, decidido por el Consejo de la Alianza en enero de $1995^{15}$. El diálogo, que en ningún caso pretende crear mecanismos equivalentes a los existentes para el Este (Asociación para la Paz o Consejo de Cooperación del Atlántico Norte), como deseaba España, afecta a cinco países -Egipto, Marruecos, Túnez, Israel y Mauritania-y tiene como primer objetivo "crear confianza" y como último reforzar la estabilidad en la región.

La creación de este diálogo OTAN-mediterráneos (inquietante a los ojos de Francia, dada su voluntad general de minimizar el papel político de la OTAN) nos muestra dos cosas. En primer lugar, la existencia de un núcleo duro del Sur, formado por Marruecos, Túnez y Egipto (más una simbólica Mauritania). En segundo lugar, la existencia de diferencias entre la UEO y la OTAN, dada, en el segundo caso, la presencia de Istael como interlocutor destacado.

La noción de geometria variable sale reforzada, tras exponer los marcos de diálogo creados por la UEO y la OTAN, que vienen a sumarse a otros ya abordados (Cinco más Cinco, Foro Mediterráneo, estructura multiforme de la política mediterránea de la Unión Europea ${ }^{16}$, etc.). El conjunto nos transmite, en definitiva, una imagen "propia de una época" en la que "es necesario, primero, analizar los problemas; en segundo lugar, buscar los regímenes más adecuados para su solución; y sólo ver entonces qué instituciones son necesarias, o sirven, para estos fines" (Ortega, 1994: 36).

\section{A modo de conclusión: Barcelona 95}

En los últimos tiempos, Barcelona ha estado en el punto de mira de los proyectos mediterráneos. Ahí está el interés de la ciudad por convertirse en la sede del Euroejército del Sur, pero, por encima de todo, la organización por la presidencia española de la conferencia euromediterránea.

¿Qué podemos esperar de la conferencia? El Consejo de Essen marcó los objetivos esenciales de la misma: "discutir en profundidad las futuras relaciones euromediterráneas [...]; abordar todas las cuestiones pertinentes en los ámbitos político, económico, social y cultural [...]; instaurar un diálogo permanente y regular sobre todos los temas de interés común».

En manos de las presidencias francesa y española se halla la tarea de establecer una agenda y de sentar airededor de una mesa a los doce interlocutores mediterráneos. Problemas no faltarı para fracasar en el empeño (relaciones greco-

15. Véase información al respecto en el boletín Nouvelles Atlantiques, núm. 2688, 25, enero de 1995 , p. 1.

16. El reciente Consejo Europeo de Fisen nos recordaba que los paises concernidos por la política mediterránea son; Argelia, Chipte, Egipto, Istael, Jordania, Líbano, Maita, Marruecos, Siria, Túnez, Turquáa y los Territorios Ocupados. 
turcas, dificultades en el proceso de paz palestino-israelí, desconfianza siria, críticas desde el norte de Europa a los regímenes árabes, etc.). Esperemos a ver cómo afecta el eterno dilema entre unidad de concepto y diversidad de hecho a Barcelona 95. En cualquiet caso, como ya apuntó en su momento la propuesta española, nos hallamos sobre todo frente a un "gesto políticon, tan sólo un pequeño paso en favor del diálogo entre los mediterráneos (europeos o no) $\mathrm{y}$ de éstos con sus vecinos del Norte.

\section{Bibliografía citada}

Aliboni, R. (1990). "The Mediterranean Dimension", en Wallace, W. (ed.). The Dynamics of European Integration. Londres: Pinter.

- (1991). «European Security across the Mediterranean». Chaillot Papers, núm. 2.

BARBÉ, E. (1984). "La región mediterránea (1). El flanco sur de la OTAN". Afers Internacionals, núm. 3, p. 5-16.

- (1991). "La dimensión meditertánea de la guerra del Golfon. Tiempo de Paz, núm. 19-20, p. 57-61.

BuZAn, B. (1991). People, States and Fear. An Agenda for International Security. Studies in the Post-Cold War Era. Nueva York: Harvester Wheatsheaf (2zed., Ia ed. 1983).

Dinan, D. (1994). Ever closer Union? An Introduction to the European Community. Londres: Macmillan.

FARIA, F. (1994). "Politiques de sécurité au Magreb. Les impératifs de la stabilité intérieure". Cahiers du Lumiar, núm. 1.

FERNANDEZ ORDONEZ, F. (1990). "Quelle structure de sécusité pour la Méditerranée?». Revue de l'OTAN, núm. 5, p. 7-11.

GINSBERG, R. (1989). Foreign Policy Actions of the European Community. The politics of scale. Boulder: Lynne Rienner.

HuNTINGTON, S. (1993). "The Clash of Civilizations». Foreign Affairs, vol. 72, núm. 3, p. $22-49$.

HUNTZINGER, J. (1989). "Les trois dimensions des relations internationales", intervención pronunciada en la apertura del II Forum Mediterráneo de Tánger, 24 de mayo de 1989.

KHADER, B. (1992). Europa y el Gran Magreb. Barcelona: Fundación Paulino Torras Domènech.

LEVEAU, R (1992). "Las migraciones magrebies $y$ la Europa comunitaria», en LOPEZ, B. España-Magreb, siglo XXI. Madrid: Mapfre.

LOPEZ GARCiA, B.; NƯNEZ VILlAVERDE, J. (1994). „Europe and the Maghreb: Towards a common space", en LuDLOw, P. Europe and the Mediterranean. Londres: Brasseys, p. $127-146$.

LORCA, A. (1992). "La política mediterránea de la CE. Una aproximación global". Taller de Estudios Internacionales del Mediterráneo (TEIM)/Centro Internacional Carlos V (UAM).

MORATINOS, M.A. (1991). "El Mediterráneo, un mar común». Politica Intemacional, núm. 978, p. 18-21.

NAIR, S. (199I). "Dos orillas, un destino". El Pais. Temas de nuestra época, 28; febrero, 1991, p. 12.

Ortega, A. (1994). La razón de Europa. Madrid: El País-Aguilar. 
SAFIR, N. (1993), "Question migratoire, sécurité et coopération en Méditerranée occidentalen. Revue Etudes Internationales, vol. XXIV, núm. 1, p. 79-102.

TOVIAS, A. (1990). Foreign Economic Relations of the European Community. The impact of Spain and Portugal Boulder: Lynne Rienner.

- (1994). "The Mediterranean Economy", en LuDlOw, P. Europe and the Mediterranean. Londres: Brasseys, p. 1-46.

WEIDENFELD, W. (1991). Challenges in the Mediterranean. The European Response (Discussion paper of the Reseatch Group on European Affairs). Gititersloh: Bertelsman Foundation. 